\title{
The Effect of Spiritual Therapy on Hope of Life in Female Students Who Referred to Isfahan University Counseling Center
}

\author{
Maryam Azizi'1, Abolfath Azizi' ${ }^{2}$, Ahmad Abedi ${ }^{3}$, Mohamad Baqher Kajbaf ${ }^{3}$, \\ Reza Ali Fallahzadeh ${ }^{*}$ \\ ${ }^{1}$ Abarkouh Paramedical College, Shahid Sadoughi University of Medical Sciences, Yazd, Iran \\ 2Department of Quran's Science \& Hadith, Science and Research Branch, Islamic Azad University, Tehran, Iran \\ ${ }^{3}$ College of Educational Psychology, University of Isfahan, Isfahan, Iran \\ ${ }^{4}$ Department of Environmental Health Engineering, School of Public Health, Shahid Sadoughi University of \\ Medical Sciences, Yazd, Iran \\ Email: "fallahzadeh4@yahoo.com
}

Received 7 December 2015; accepted 23 January 2016; published 26 January 2016

Copyright (C) 2016 by authors and Scientific Research Publishing Inc.

This work is licensed under the Creative Commons Attribution International License (CC BY).

http://creativecommons.org/licenses/by/4.0/

c. (i) Open Access

\section{Abstract}

The purpose of the present study was to examine the effectiveness of spiritual therapy on female students' hope who referred to Isfahan University counseling center. The methodology used was experimental. The study population was confined to the female students referring to Isfahan University counseling center. 30 students were randomly selected and divided into two experimental and control groups. Adult Hope Scale was used as the research tool. The obtained results were analyzed using the analysis of covariance and they showed that spiritual therapy is effective on increasing students' hope.

\section{Keywords}

Spirituality, Spiritual Therapy, Hope, Students

\section{Introduction}

Hope which is the outcome of knowledge and wisdom about the world is the base of all human efforts, the source of change in society and the way to eternal happiness. The very fact of having hope for a bright future gives one a good feeling and a happy mood, creates motivation and pushes him to the right life activities. If man

\footnotetext{
${ }^{*}$ Corresponding author.
}

How to cite this paper: Azizi, M., Azizi, A., Abedi, A., Kajbaf, M. B., \& Fallahzadeh, R. A. (2016). The Effect of Spiritual Therapy on Hope of Life in Female Students Who Referred to Isfahan University Counseling Center. Psychology, 7, $126-131$. http://dx.doi.org/10.4236/psych.2016.71015 
was aware of his time of death he would do nothing. He wouldn't marry or start a job and he would content himself with the daily activities. It is unawareness and hope that motivates him to study, embark on a vocation, marry and build a family.

From the perspective of Islam, the only thing that can bring peace and tranquility into man's life and free him from everyday tensions is the remembrance of God. According to Allameh Tabatabaie, man tries to reach happiness and stay away from misery. He resorts to every available means. But, although these tools and means are powerful and effective in some respects, they are weak and useless in some others, except for the magnificent God who is almighty and all-powerful (Tabatabaie, 1987).

According to Quran, hope is an important factor in man's life and drives him into work. For instance, it states the hope that the prayer will be answered by God is the reason and motivation for prayer (The Holy Qur'an, al-Baqarah, 2: p. 186) (Makarim Shirazi, 2005). It is the hope for a better future in this world and the hereafter that makes man review his beliefs, actions and reactions and modify his deeds and behavior (The Holy Qur'an, Yunus 10: 7 \& 8) (Makarim Shirazi, 2005). Such verses show the importance of hope and its role in life. It has been proven that hope has such a crucial and positive role that without it life would be unbearable. Those who lose their hope get depressed, feel absurd and may commit suicide. Hope can hold back depression and prevent people from committing suicide. Actually, besides motivating and inspiring, this can be regarded as the most important function of hope.

Moreover, according to different Hadiths, the great Imams, going through life crises and difficulties, reached tranquility and peace of mind through praying God. This is the only way that man's nature can calm down and experience a feeling of indescribable joy. Not having faith in God, man is confined to this material world. By believing in God, however, he can connect to His unlimited source of knowledge, wisdom, power and mercy in such a way that he only asks Him for whatever he needs and is not afraid of anything or anyone. That's why Imam Sadeqh (AS) said: "God made faith such a security for man that if he is alone on the peak of a mountain, he has no fear and fright” (Majlesi, 70: p. 111) (Majlesi, 1956).

Furthermore, many eastern and western scholars emphasize that modern man's problem is basically related to his need for religion and spiritual values. For instance, the well-known historian, Arnold J. Toynbee believes the crisis the Europeans are encountering in the current century has its roots in their spiritual poverty. He points out that the only way to prevent the West from crumbling is to turn back to religion and spirituality (Nejati, 1989).

Spiritual and religious beliefs are sources of hope, meaning and peace. Pargament (2000) proposed a theoretical framework for the role of religion in relation to coping behavior. According to this framework, people rely on an orientation system of beliefs, actions and relationships. For most people, religion and spirituality are parts of this general orientation. It is argued that when the level of stress is increased, the religious orientation system functions as a means to cope with the situation. He admits that through the coping process people try to keep the feeling of meaningfulness (Pargament, Koenig et al., 2000).

On the other hand, hopeful people always have more "agencies" and "pathways" to pursue their goals and when they face an obstacle they can maintain their motivation and use alternative pathways. Hopeless people, however, have fewer pathways. So, encountering obstacles, they lose their motivation and experience negative emotions which in turn lead to depression. In fact, hopelessness is one of the components of depression. Furthermore, hopelessness deprives one of most of his opportunities and thus decreases his effectiveness. Numerous therapeutic method shave been developed to prevent its adverse consequences. Psychotherapeutic approaches, behavior change methods and other approaches are trying to help human overcome these difficulties. Nowadays, the variety of these methods is to the extent that makes choice difficult (Snyder, 2003).

Several studies have shown that positive religious worldview (viewing God as benevolent) has a positive impact on quality of life, while a negative religious worldview (viewing God as punishing) causes depression and anxiety. In Elizabeth Jesse, Schoneboom and Blanchard (2005) research on content analysis of the spiritual domain of the hope theory on pregnant women, the importance of spirituality is emphasized. Spirituality can be regarded as a new source of mental health care during pregnancy.

Many studies have examined the impacts of spirituality on depression and mental health and have found a negative relationship between spirituality and depression symptoms and a positive relationship between spirituality and mental health. This strong relationship should lead counselors and mental health professionals to consider using the advantages of this source (Dein, 2010).

Smith (2008) and his students conducted a statistical analysis on 100000 subjects and found a negative correlation between religion and depression. They showed that religion improves the therapy outcome of mental and 
medicine-taking patients. It should be noted that depression is a serious disorder that should be treated because not only it is an emotional disorder but also it increases the suicide rate.

Jasemi Zargani et al., (2014) compare the Effectiveness of Cognitive-behavior therapy and spirituality therapy in reduction of students' depression symptoms. The result showed that improvement of experimental groups was significantly greater than control group, but there was no significant difference in improvement rate between two intervention (Cognitive-behavior therapy in group and spirituality therapy) groups.

A review article, examining the results of 68 studies has reported a relationship between depression and suicide. 57 studies out 68 have shown that there is a lower rate of suicide or a negative attitude toward suicide among religious people. According to a cross-sectional study in Canada, religious tendency is related to lower rate of suicide and religious teachings might prevent suicide. So conducting further research is needed to evaluate the use of spirituality as a treatment method for psychological problems like anxiety and depression.

Regarding the mentioned research results, this study tries to examine the effectiveness of spiritual therapy on hope of female students referring to Isfahan University counseling center.

\section{Methodology}

In this experimental research, pretest-posttest design, following up the control group and random selection of subject was used in which the independent variable is increasing hope methods (teaching spirituality therapy) and the dependent variable is the subjects' scores on Adult Hope Scale.

\subsection{Study Population, Sample and Sampling}

The study population in this research is the female students referring to Isfahan University counseling center in 2013 the academic year. To select the subjects, random sampling was used. First, 30 students referring to the counseling center were randomly selected and then they were divided into two groups of 15 each.

\subsection{Measurement Tools}

Snyder Hope Scale: The 12-item measure of level of hope by Snyder (1991, as quoted by Snyder \& Patterson, 2000 ) is designed for 15 years old and older. It is divided into two subscales of agency and pathway and can be answered in a short time (2 to 5 minutes). Subjects respond on a four point continuum ( $1=$ definitely false, to 4 = definitely true). Questions 3, 5, 7 and 11 are fillers and are not scored. Questions 2, 4, 6 and 8 measure pathways subscale and questions 12, 10, 9 and 1 measure agency subscale. The hope score is the sum of these two scores. The total score can be between 8 and 32. A research carried out by Golzari (2008) resulted in an internal consistency score of $\alpha=0.89$.

\subsection{Data Analysis}

The obtained data were evaluated by using SPSS 16.00 (Statistical Package for Social Sciences). In the analysis of data, there is a strong correlation between the Hope Scale and the other scales measuring similar psychological processes. For example, a 50 to 60 percent correlation between Hope Scale scores and Scheier and Carver Optimism Scale is observed. There is also a negative correlation between these scores and Beck Depression Inventory $(-0 / 42-0 / 51)$. Furthermore, content validity of this scale is also confirmed by clinicians.

\subsection{Intervention Strategy}

Teaching spiritual therapy: In the last two decades, many empirical studies of aging-associated diseases have reported protective effects of religious involvement on mental well-being, life satisfaction, depression, happiness and physical health (Levin \& Markides, 1986; Laurence et al., 2009; Lotfi \& Fallahzadeh, 2013).

Many studies have reported that depressed people are trying to use spirituality and religion to deal with the depression caused by their illness. By spirituality the man's commitment to religion is meant which can be measured by religious commitment, spiritual experiences, faith or religious motivation and so on. These different aspects of the experience are sometimes called spirituality or internal religiosity. Spirituality is attributed to the beliefs and behaviors that are based on the consumption that life has transcendental aspects (spiritual not physical) that intimately connects man with God and develops a range of virtues in him (Seligman, 2004).

Spirituality therapy based treatment methods, First session: Establishing a therapeutic relationship, creating 
hope and encouragement, giving feedback, addressing the main complaint of the clients, conceptualization and preliminary formation of the client's problem, drawing the diagram of interaction among body, imagination, mind and heart that can form and escalate hopelessness based on psychological models and spiritual approaches. Second session: Addressing the clients' problems through making a list of their main problems and determining their priority, teaching strategies to break worry habit. Explaining the major insights introduced in Quran which can change man's perception of life. Discussing and thinking about the inner feelings and moods and finding the defective attitudes, emotions and behavioral patterns creating hopelessness and worry. Third session: Identifying and discussing the underlying principles of spiritual life. Putting emphasis on human needs and offering several solutions based on spirituality for refreshment, maintaining youth and vitality, relieving and handling boredom, frustration and anger and also resolving problems like insomnia, money worries and finding job. Fourth session: Talking about prayer and its role in human life and excellence. Explaining prayer benefits for knowing human and his needs, improving man's moods and attitudes, creating divine beliefs and values in human life. Teaching how to pray according to the principles mentioned in Islamic sources. Practicing to modify sentences and what they say out of hopelessness and to put them in the form of prayer and asking God. Fifth session: Talking and discussing about hope and trusting God with the problems they may face in future. Explaining, teaching and practicing trust and reliance on God. Sixth session: Talking about Knowing God and man's relationship with Him (understanding human needs, his negative traits and characteristics, God's mercy, grace, forgiveness and protection towards man, oneness of God's attributes and the universe and repentance). Seventh session: Practicing donation and generosity (based on sparing what you have in order to...), assigning home practices (donation and generosity, being respectful in the presence of God, thinking about prayer, recommend reading and thinking about prayer in order to reach peace in anxious times). Eighth session: Establishing core beliefs that the decrees of God are all-wise, fair and purposeful. Looking for meaning in hardships and sufferings and showing patience in difficulties. Recognizing one's personal virtues and life's meaningfulness through creative and experiential values and reviewing what the clients have learned and their impressions and personal experiences during the sessions. Reminding how to apply various skills they have learned during the sessions in social and real-life situations that can trigger anxiety related thoughts and symptoms.

\subsection{Data Analysis}

In this research, mean, standard deviation and covariance is used to analyze the data.

\section{Results}

The mean and the standard deviation of hope scores of different groups in pretest, posttest and follow-up are shown in Table 1. These results show that there is a noticeable difference in the mean hope scores of the group under therapy at posttest and follow-up compared with the pretest scores.

The results illustrated in Table 2 suggest that considering pretest scores, intervention (spiritual therapy) has resulted in a significant difference between experimental and control group at posttest $(P<0.000)$. The efficacy was $60 \%$. It means that $60 \%$ of posttest variance (increasing hope) has been related to spiritual therapy. Furthermore the statistical power is $100 \%$. So it can be concluded that spiritual therapy has been effective in increasing the students' hope.

The results illustrated in Table 3 suggest that considering pretest scores, intervention (spiritual therapy) has resulted in a significant difference between experimental and control group at posttest $(P<0.000)$. The efficacy was $53 \%$. It means that $53 \%$ of posttest variance (increasing hope) has been related to spiritual therapy. Furthermore the statistical power is $100 \%$. So it can be concluded that spiritual therapy has been effective in increasing students' hope.

Table 1. The mean and the standard deviation of hope scores of different groups in pretest, posttest and follow-up.

\begin{tabular}{|c|c|c|c|c|c|c|}
\hline & \multicolumn{2}{|c|}{ Pretest } & \multicolumn{2}{|c|}{ Posttest } & \multicolumn{2}{|c|}{ Follow-up } \\
\hline & Mean & S.D. & Mean & S.D. & Mean score & S.D. \\
\hline Spiritual therapy & 15.83 & 2.167 & 18.08 & 2.539 & 18 & 2.374 \\
\hline Control & 15.75 & 2.050 & 15.75 & 1.815 & 15.67 & 2.103 \\
\hline
\end{tabular}


Table 2. Analysis of covariance of hope scores of experimental and control groups at posttest.

\begin{tabular}{cccccccc}
\hline Source of change & Total mean & $\begin{array}{c}\text { Degree of } \\
\text { freedom }\end{array}$ & Square mean & F & Significance level & Eta squared & Statistical power \\
\hline Experimental group & 87.226 & 1 & 87.226 & 91.858 & 0.000 & 0.814 & 100 \\
Control group & 30.489 & 1 & 30.489 & 32.108 & 0.000 & 0.605 & 100 \\
Error & 19.941 & 21 & 0.950 & & & & \\
\hline
\end{tabular}

Table 3. Analysis of the covariance of hope scores of experimental and control groups at follow-up.

\begin{tabular}{cccccccc}
\hline Source of change & Total mean & $\begin{array}{c}\text { Degree of } \\
\text { freedom }\end{array}$ & Square mean & F & Significance level & Eta squared & Statistical power \\
\hline Experimental group & 84.572 & 1 & 84.572 & 68.060 & 0.000 & 0.764 & 100 \\
Control group & 30.521 & 1 & 30.521 & 24.562 & 0.000 & 0.539 & 99 \\
Error & 26.095 & 21 & 1.243 & & & & \\
\hline
\end{tabular}

\section{Discussion and Conclusion}

The research results demonstrated that intervention in the form of spiritual therapy is effective in increasing students' hope. The findings of this research, in this regard, further confirm the efficacy of spiritual therapy in the treatment of depression and increasing hope, and are also consistent with the results of earlier researches. These results are consistent with Levin and Markieds (1986), McCullough and Laurenceau (2005), Elizabeth et al. (2005), Simon Dein (2010), Hosseini et al. (2012), Jasemi Zargani et al. (2014) researches.

To explain the results of the study, it can be said that this result is the outcome of the coherence of religious systems that depict the world as ordered. By giving insight into the universe, man's true nature, death and after death and providing trust and encouragement, religious beliefs help people to tolerate life suffering and also help them to identify matters that can be changed and those that cannot and peacefully surrender to what that cannot be changed (accepting divine justice and wisdom) and taking action on what they can change (having reliance on God). Therefore, most religions satisfy man's need to predict and control events through trusting in God, controlling events, hope and expectation of reward or prayer and rituals.

The research has found a negative relationship between spirituality and depression and a positive relationship between spiritual and mental health. Because of this strong relationship, counselors and mental health professionals should consider using the advantages of this source.

To clarify this, we can mention that the mental world of human being is more important than his body and physical world. One of the recent concepts, which have been the center of attention in the last few years, is the concept of optimism. It is one of the positive attitudes of human being in which the positive consequences are considered as the total, internal and permanent factors. When the human understanding is accompanied by a positive concept of oneself, besides helping him in ordinary situations, it will help him in stressful and threatening situations (Zakery et al., 2014).

\section{References}

Dein, S., Cook, C., Powell, A., \& Eagger, S. (2010). Religion, Spirituality, and Mental Health. Theoretical and Clinical Perspectives, 28-32.

Golzari, M. (2008). Hope to Validate the Questionnaire Adults. Tehran: Allameh Tabatabai University.

Hosseini, M., Davidson, P., Salehi, A., \& Fallahi, M. K. (2012). The Effect of Spiritual Training on Anxiety of CABG Candidates in Iran. Heart, Lung and Circulation, 21, 143-316. http://dx.doi.org/10.1016/j.hlc.2012.05.707

Jasemi Zargani, M., Golzari, M., Aghayousefi, A., \& Fathi Ashtiyani, A. (2014). Comparison of the Effectiveness of Cognitive-Behavior Therapy and Spirituality Therapy in Improvement of Students’ Depression. Clinical and Experimental Psychology, 1, 46-59.

Jesse, D. E., Schoneboom, C. M., \& Blanchard, A. (2005). Content Analysis of the Spirituality Domain of the Theory Hope. Academic Research Library, 5, 442. 
Laurence, B., Sylvia, M., Christiane, G., Pierre-Yves, B., Isabelle, R., Claude, L., \& Philippe, H. (2009). Religion and Spirituality: How Clinicians in Quebec and Geneva Cope with the Issue When Faced with Patients Suffering from Chronic Psychosis. Community Mental Health, 46, 77-86.

Levin, J. S., \& Markides, K. S. (1986). Religious Attendance and Subjective Health. Journal for the Scientific Study of Religion, 25, 31-40. http://dx.doi.org/10.2307/1386061

Lotfi, M., Fallahzadeh, R., Salmani, I., Askarnejad, A., Hajian, N., \& Fallahzadeh, S. (2013). Correlation between Religious Beliefs and Quality of Life in Dialysis Patients Referred to Shahid Rahnemoon Hospital, Yazd-2012. JCHR, 2, 220-228.

Majlesi, M. B. (1956). Beharolanvar. Alaslamyh of Books. Qhom: Bita.

Makarim Shirazi, N. (2005). Holy Quran, The Translation. Tehran: Darolkotobel Eslamiyah.

McCullough, M. E., \& Laurenceau, J. P. (2005). Religiousness and the Trajectory of Self-Rated Health across Adulthood. Personality and Social Psychology Bulletin, 31, 560-573. http://dx.doi.org/10.1177/0146167204271657

Nejati, M. (1989). The Qhoran and Psychology, Translation of the Arab Abbas. Mashhad: The Publication of the Islamic Research.

Pargament, K. I., Koenig, H. G. et al. (2000). The Many Methods of Religious Coping: Development and Initial Validation of the RCOPE. Journal of Clinical Psychology, 56, 519-543. http://dx.doi.org/10.1002/(SICI)1097-4679(200004)56:4<519::AID-JCLP6>3.0.CO;2-1

Seligman, M. E. P. (2004). Authentic Happiness: Using the New Positive Psychology to Realize Your Potential for Lasting Fulfillment. New York: Free Press.

Smith, J., \& McSherry, W. (2008). Spirituality and Child Development: A Concept Analysis. Journal of Advanced Nursing, 45, 307-315.

Snyder, C. R., \& Peterson, C. (2000). Handbook of Hope: Theory, Measures \& Applications. San Diego, CA: Academic Press.

Snyder, L. (2003). Satisfactions and Challenges in Spiritual Faith and Practice for Persons with Dementia. Dementia, 23, 299-313. http://dx.doi.org/10.1177/14713012030023002

Tabatabaie, M. (1987). Al-Mizan Interpretation. Tehran: Allameh Tabatabaie Foundation.

Zakery, J., Makari, R., Pir Cheraghali, A., \& Zahedi, O. (2014). The Relationship between Religious Beliefs, Optimism and Moral Health of the University Students. Journal of Educational and Management Studies, 4, 415-419. 